\title{
Results on Harmonic and Flicker Control in Buenos Aires Public Distribution Services
}

\author{
Pedro Issouribehere, Gustavo Barbera, Jorge Martínez, and Alejandro Galinski
}

\begin{abstract}
The public electric services in Buenos Aires metropolitan area are rendered by 3 private companies, called A, $B$ and $C$ in the text. The control is carried out by the Ente Nacional Regulador de la Electricidad (ENRE). The Instituto de Investigaciones Tecnológicas para Redes y Equipos Eléctricos (IITREE) of Universidad Nacional de La Plata (UNLP) collaborates in technical assistance.

The disturbance - harmonics and flicker - Monitoring Programs started at the beginning of 1997, that is why, so far, an important amount of measurements have been collected.

The levels of harmonic representative magnitudes, its behavior throughout the day and the year are analyzed. These levels are compared between the three Utilities in different years.

The procedures used for the evaluation of penalties in harmonic and flicker normalized measurements are explained, showing then the transgression of the allowed levels and the unitary sums of the penalties.
\end{abstract}

Keywords-- Flicker, Harmonics, Measurements, Monitoring Programs, Statistics, Penalties.

\section{INTRODUCTION}

$\mathrm{T}$ HE procedure for disturbance control is performed in two levels. On one hand representative magnitudes of harmonics and flicker are measured by means of a Monitoring Program (MP) that comprises an important number of network areas (MP 1); and on the other hand IEC [5] [6] normalized measurements are carried out at those points that are justified by the detected levels in MP 1(MP 2).

MP 1 has the aim of supervising the level of disturbances in wide areas of the low voltage network, by means of harmonic and flicker indicators. The Utilities perform 670 measurements a month (A and B Utilities 300, C Utility 70) in points at the network chosen at random.

The places where the measurements of MP 2 are carried out are chosen from the results of MP 1. 45 measurements are

P. E. Issouribehere is with Instituto de Investigaciones Tecnológicas para Redes y Equipos Eléctricos - Laboratorio de Alta Tensión, Universidad Nacional de La Plata (IITREE-LAT UNLP), La Plata, B1900AMF Argentina (e-mail: pedroi@iitree.ing.unlp.edu.ar).

G. A. Barbera is with Instituto de Investigaciones Tecnológicas para Redes y Equipos Eléctricos - Laboratorio de Alta Tensión. Universidad Nacional de La Plata (IITREE-LAT UNLP), La Plata, B1900AMF Argentina (e-mail: gbarbera@iitree.ing.unlp.edu.ar).

J. L. Martínez is with Ente Nacional Regulador de la Electricidad (ENRE), Buenos Aires, C1106ACX Argentina (e-mail: jmartinez@enre.gov.ar).

A. V. Galinski is with Ente Nacional Regulador de la Electricidad (ENRE), Buenos Aires, C1106ACX Argentina (e-mail: agalinski@enre.gov.ar). performed a month (A and B 18, C 9). If the reference levels are exceeded for more than $5 \%$ of the time, the Utility is fined. [7], [4].

In this paper the results obtained in the first three years of measurements are analyzed.

\section{ANALYSIS OF HARMONIC RESUlTS OF MONITORING PROGRAM 1}

\section{A. General Considerations}

The Disturbance Monitor used in this program only measures the Total Harmonic Distortion (THD, usually in percent values) defined as:

$$
T H D=\sqrt{\sum_{i=2}^{15}\left(\frac{U_{i}}{U_{1}}\right)^{2}}
$$

Where $U_{i}$ is the amplitude of harmonic voltage of order $i$ and $U_{1}$ the amplitude of the fundamental voltage.

Each measurement lasts a week, making an average value record (also called interval) every 15'. In Fig. 1 the profile of a measurement is presented as an example.

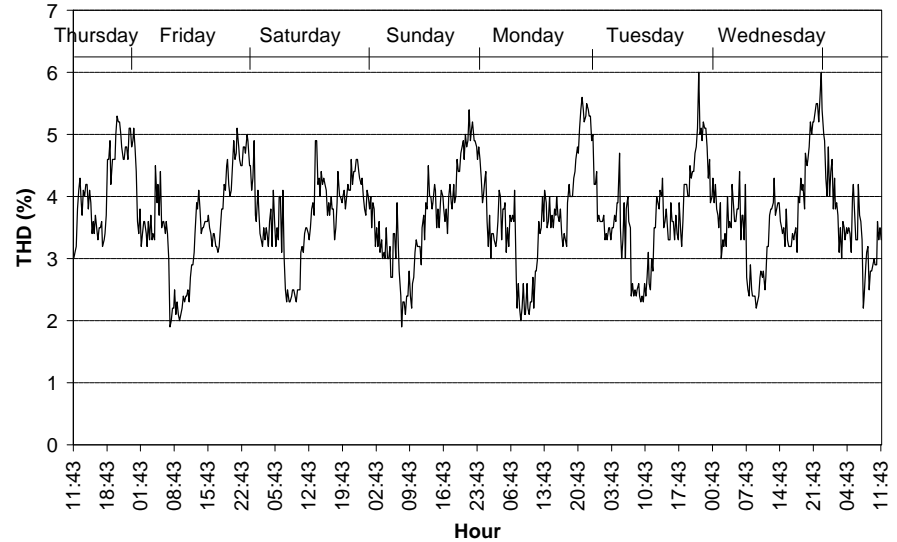

Fig. 1. Weekly measurement of THD.

A way of analyzing each measurement is by statistical means. Thus, Histograms and Cumulative Distributions Functions (CDF) are used [1].

In Fig. 2, the histogram and CDF for Fig. 1 measurement are shown.

On that graph, the 5\% value of the $\mathrm{CDF}$ has been highlighted. This is a parameter called Percentile $95\left(\mathrm{P}_{95}\right)$, which will be mentioned in many opportunities in this paper. It indicates, in Fig. 2 case, that the THD value is exceeded only by $5 \%$ of all the 15 -minute records which conform a weekly 